\title{
RUA DAS CAMÉLIAS
}

Cia Vórtica

Após oito meses em São Paulo, trabalhando como assistente de direção do grupo Teatro da Vertigem na montagem do

espetáculo "Karta ao pai - O Filho", Gabriela Luque, diretora de "Rua das Camélias", retornou a Belo Horizonte e montou no final de 2015 a Companhia Vórtica, juntamente com os atores Ariadina Paulino, Edsel Duarte, Flávia Pacheco, Gabriel Zocrato, Istéfani Pontes, Marina Abelha e Regina Ganz. Interessados em pesquisar narrativas de espaço e site specific, deram inicio a uma pesquisa sobre as mulheres (cis e trans) em situação de prostituição que trabalhavam em hotéis no centro de $\mathrm{BH}$; região marginalizada, mas que atrai jovens de classe média em busca de festas em espaços "alternativos", blocos de carnaval e que é palco da Virada Cultural.

Levantando questionamentos em relação às identidades das mulheres que pulsam submersas em preconceito e fantasia a equipe se dedicou ao longo de 13 meses a pesquisas e levantamento de material, durante esse tempo houve uma imersão de quatro meses nos hotéis da Rua dos Guaicurus onde o elenco passou a ir semanalmente, em variados horários, para conversar com as mulheres e observar como elas interagiam entre elas, com os clientes e com o espaço. A dramaturgia, concebida pela própria Cia Vórtica, teve a colaboração do jornalista, dramaturgo e diretor Daniel Toledo e da dramaturga Gabriela Figueiredo, e deixa claro que o

texto não pretende ser um porta voz das prostitutas. A ideia é apresentar o que elas sentiram vontade de compartilhar com o grupo durante a pesquisa e propor uma reflexão sem levantar bandeiras ou julgamentos.

Para a realização do espetáculo a Cia realizou um financiamento coletivo que alcançou sua meta antes mesmo do final do prazo com anta Casa ocuparam um estabecido em antigo hotido de prosulo estreou em novembro de 2016 com 12 apresentações, voltou em fevereiro de 2017 com 9 apresentaçoes na 43a Campanh de Popularização do Teatro e Dança de Belo Horizonte e mais 
4 apresentações em março de 2017. Sucesso de crítica e de público, todas as temporadas tiveram apresentações esgotadas.

Em janeiro de 2017 a Cia Vórtica recebeu o prêmio Beagá Cool de iniciativa mais cool de Belo Horizonte em 2016 na categoria artes pelo espetáculo Rua das Camélias.

No ano de 2018 a peça participou da $44^{\text {a }}$ Campanha de popularização do Teatro e Dança de Belo Horizonte e também do quadro de espetáculos da mostra mineira da $14^{\mathrm{a}}$ edição do FIT-BH Festival Internacional de Teatro Palco e Rua de Belo Horizonte, um dos mais importantes festivais de artes cênicas do Brasil. Uma rua. Um lugar da cidade. Esquinas, portões vermelhos, escadas, corredores e luzes coloridas. Um comércio. Uma profissão tabu. Um pedaço de Belo Horizonte que ninguém conhece. Quem conhece, murmura. E assim a rua segue, seletivamente esquecida. $E$ assim seguem suas mulheres. Invisíveis.
Rua das Camélias ocupa um hotel de 'alta rotatividade' e procura revelar um pouco da vida que existe atrás do mito. $O$ que é real? O que é fantasia? Quem foi Hilda Furacão? Quem são as mulheres que hoje alugam os quartos destes hotéis? que procuram? O que isso tem a ver conosco?

A Cia Vórtica traz ao público seu primeiro espetáculo, uma peça em forma de interrogação. Não poderíamos (e não

procurávamos) fazer um teatro de verdades e posicionamentos bem definidos. A rua são muitas, com seus becos, janelas, esquinas, paralelas e perpendiculares. Sua alma não pode ser materializada em palavras fixas, sob o risco de desvanecer por completo, deixando o locutor com modos de inocencia por complo, deixando o locutor com modos de inocencia ou a que nos cabia, apenas, trazer os holofotes. lluminar onde os olhos ate então não alcançavam, e deixar o sentindo se construir naqueles que virão. Precisamos Falar sobre a Rua dos Guaicurus. A porta está aberta, basta entrar.

\section{WWw.facebook.com/ruacamelias}

\section{www.facebook.com/ciavortica}




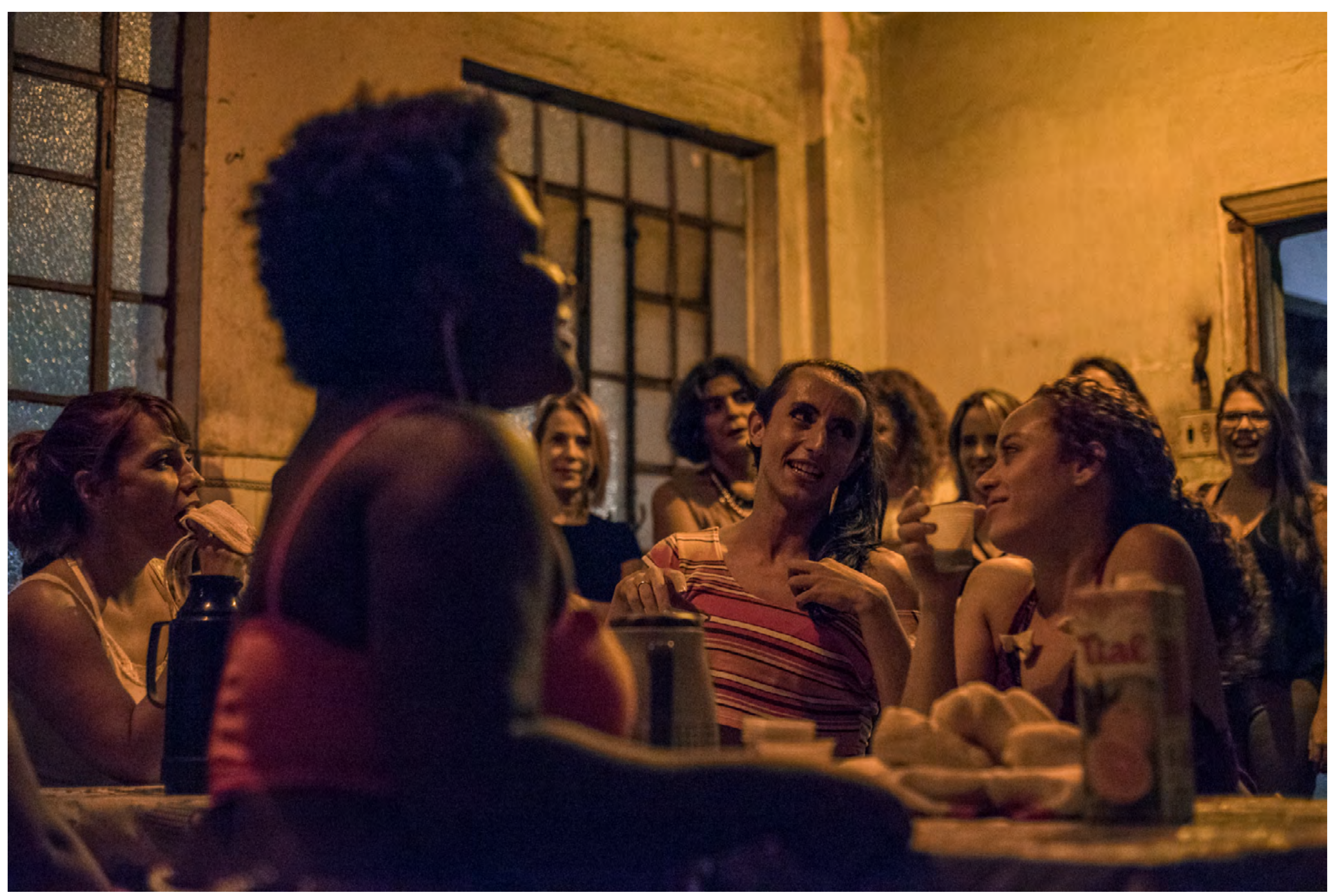




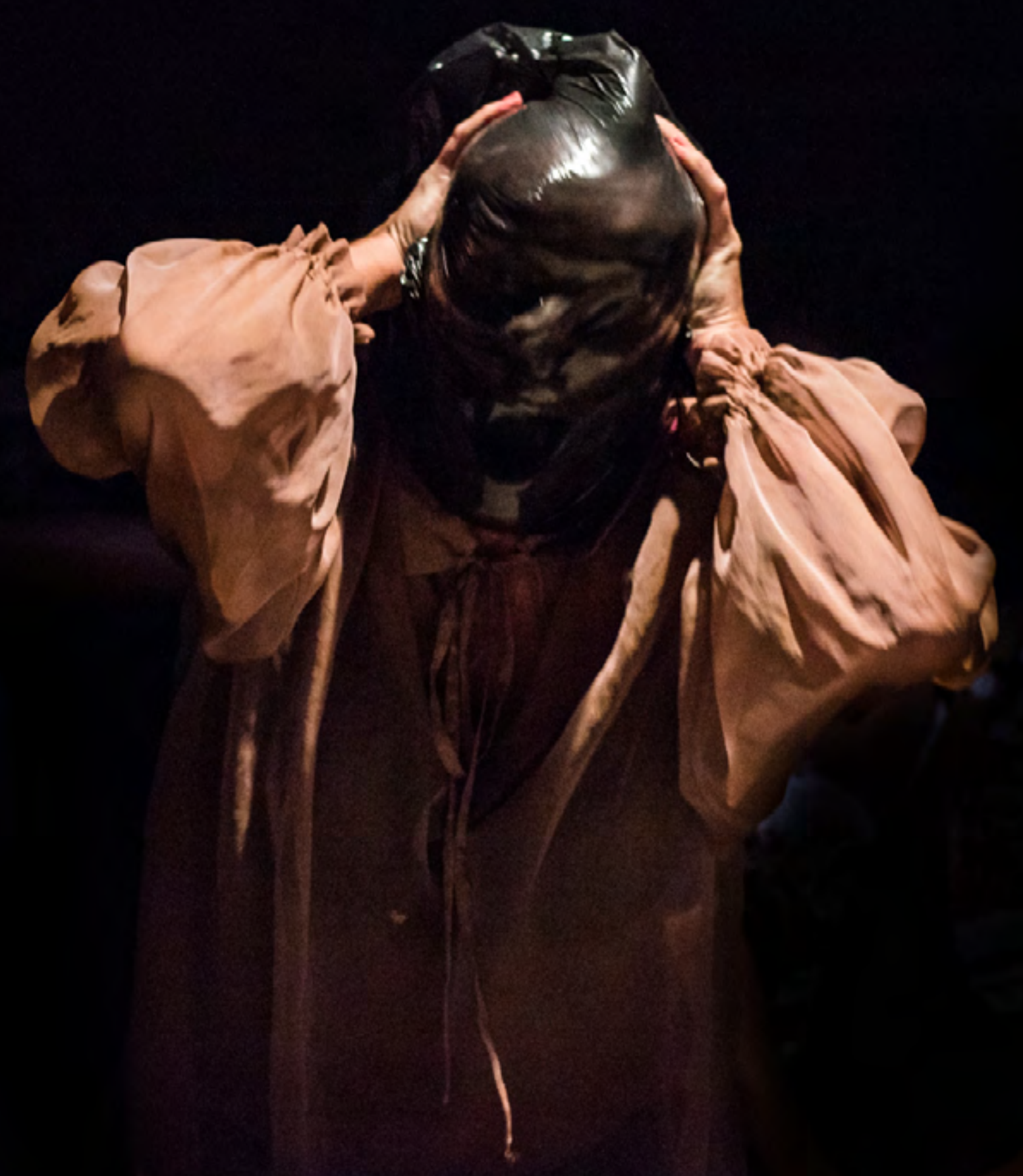




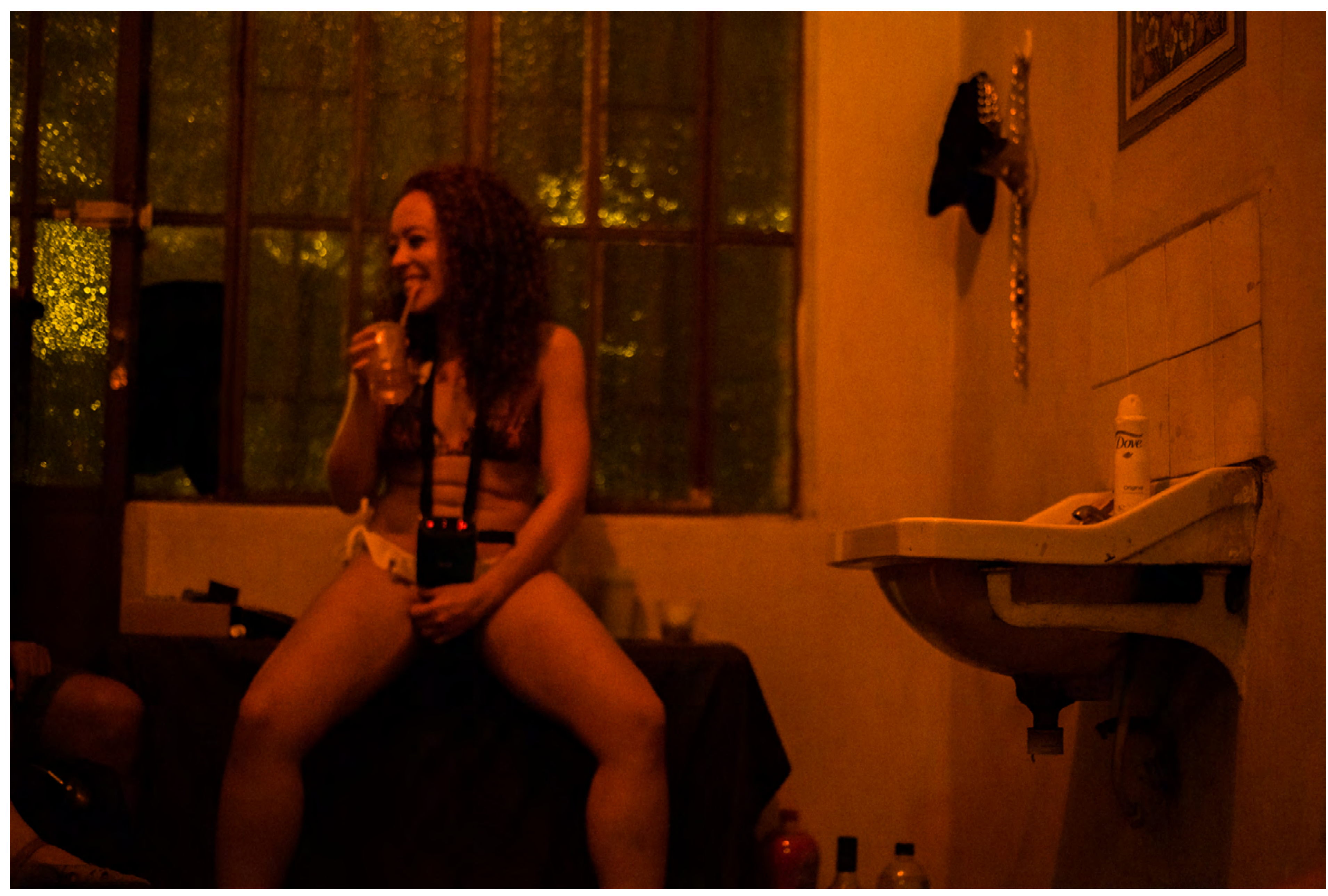




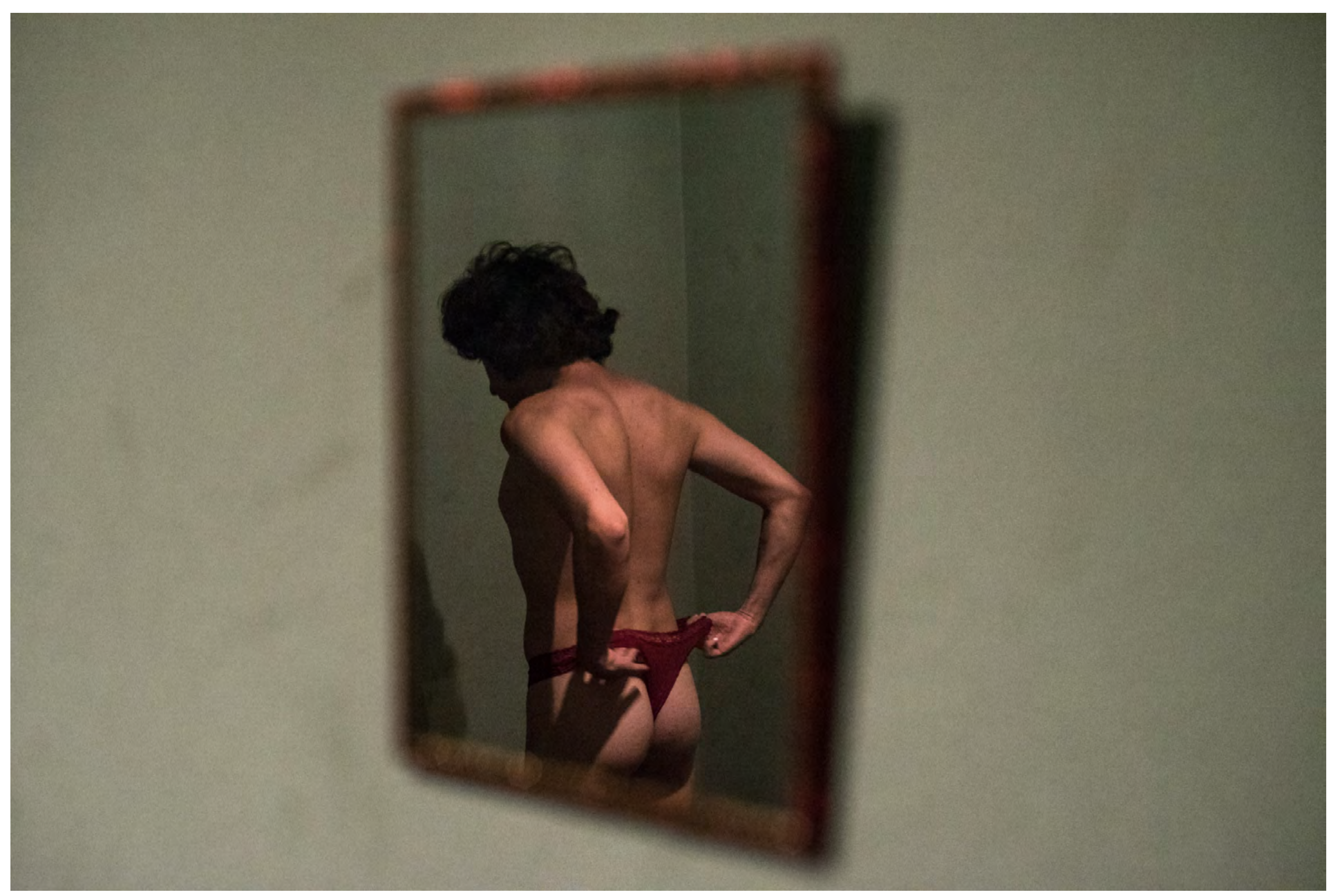




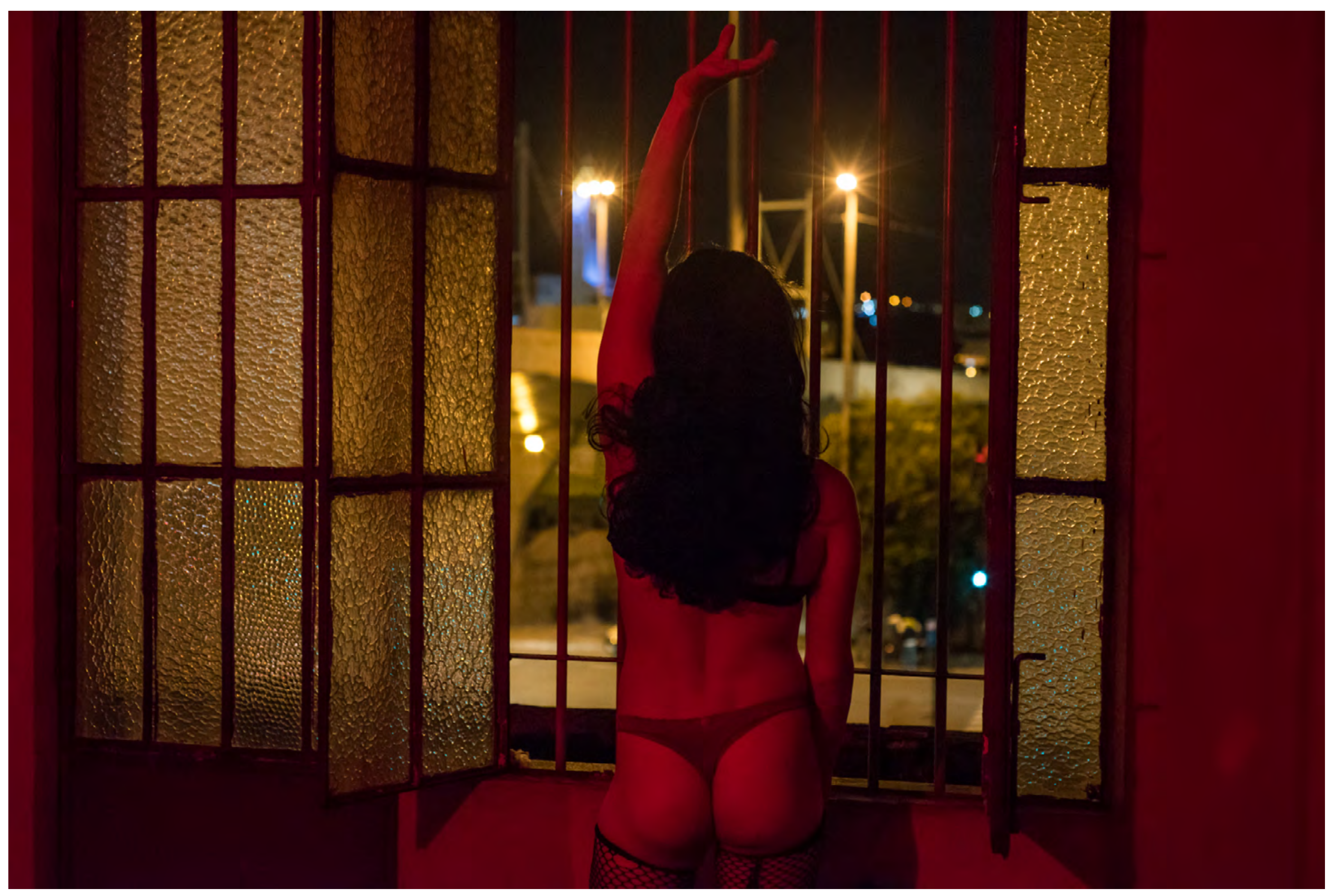




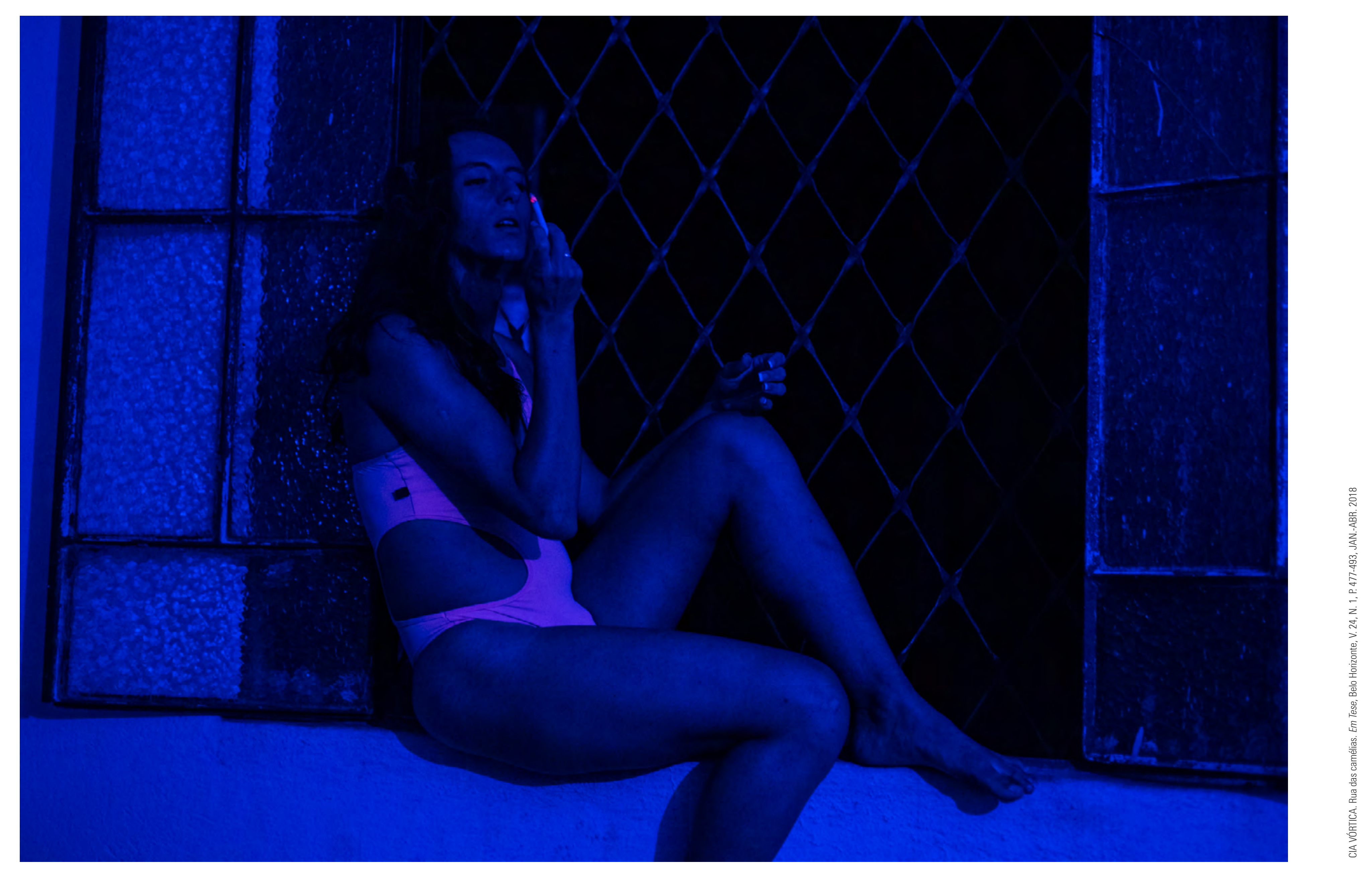




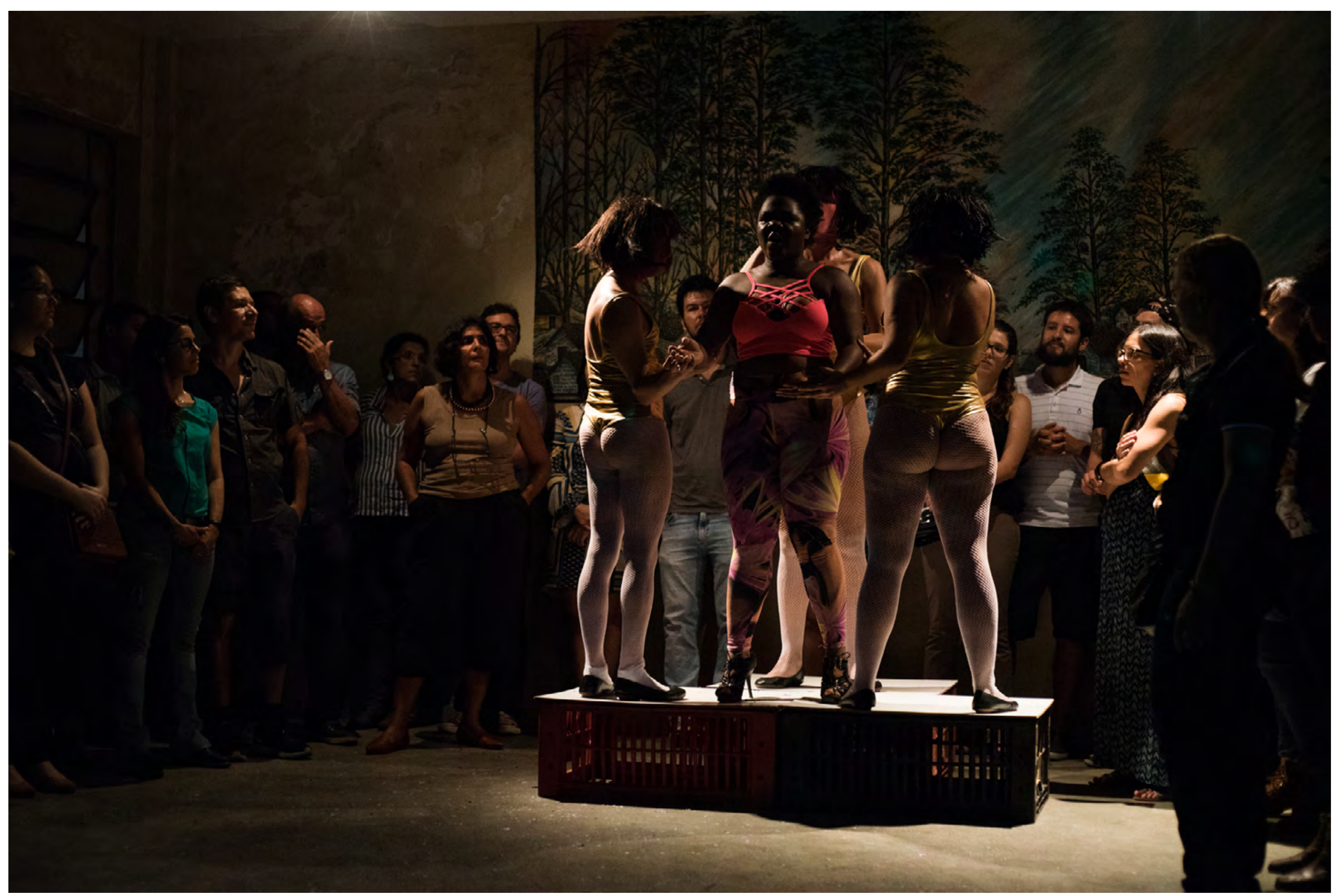




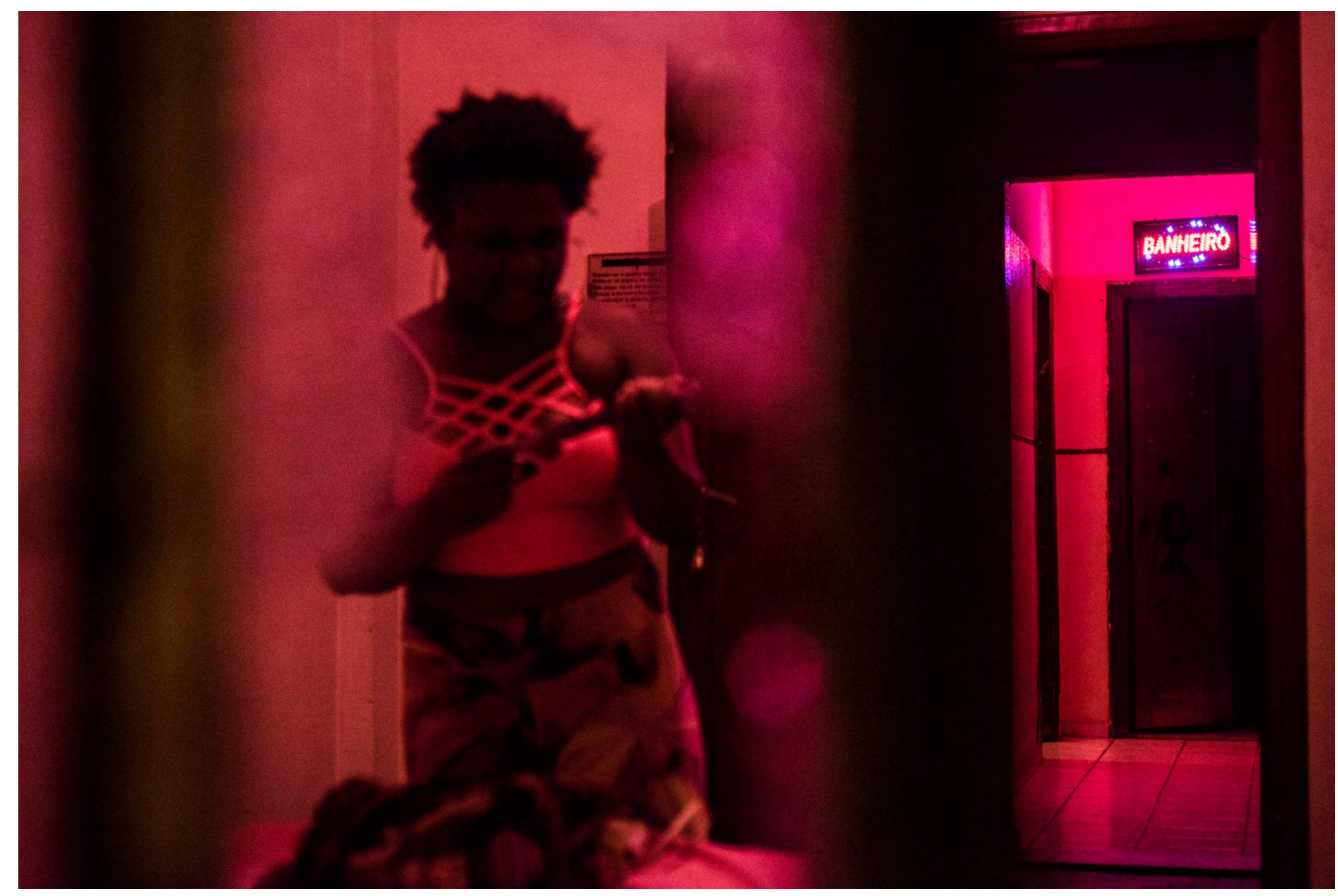




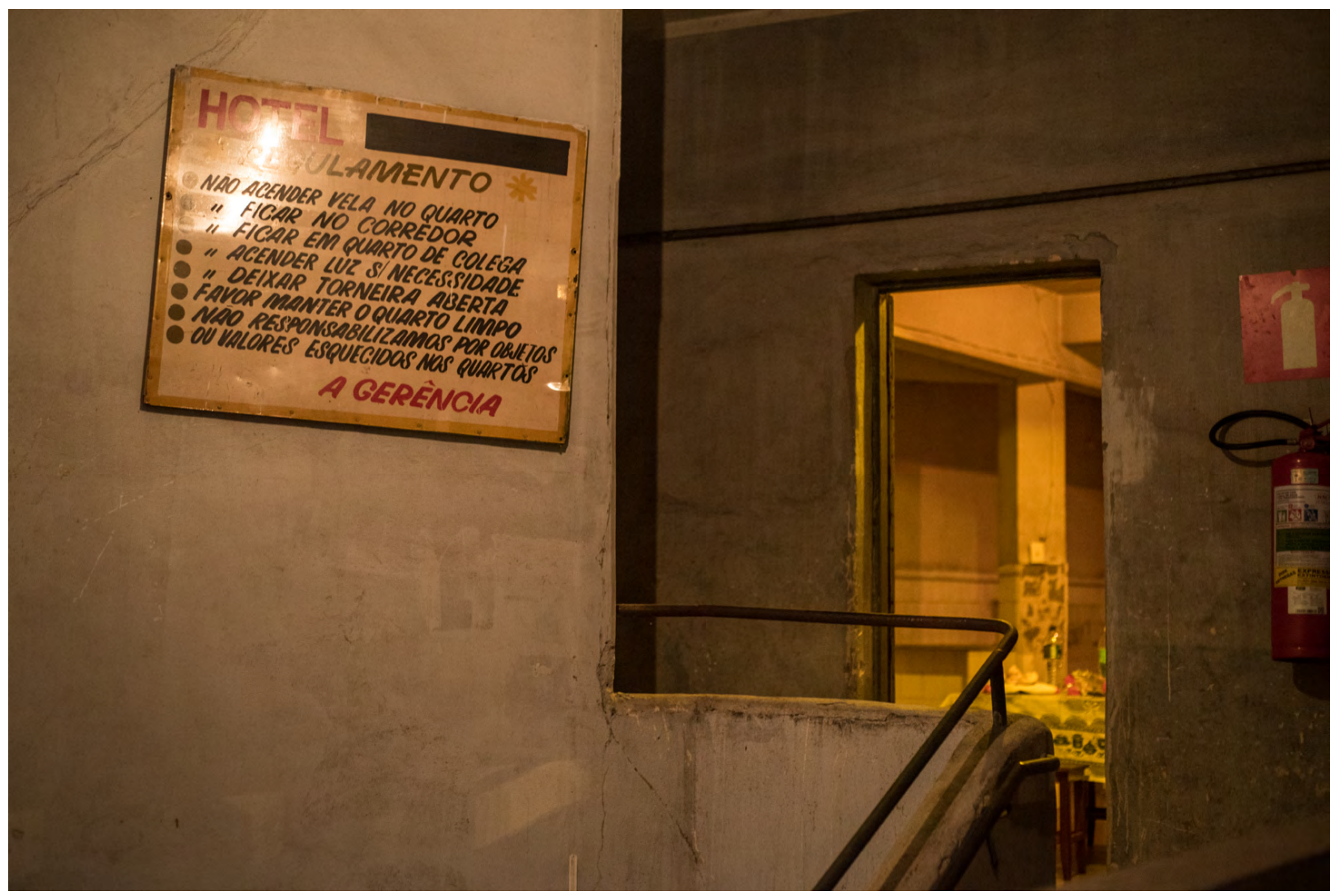




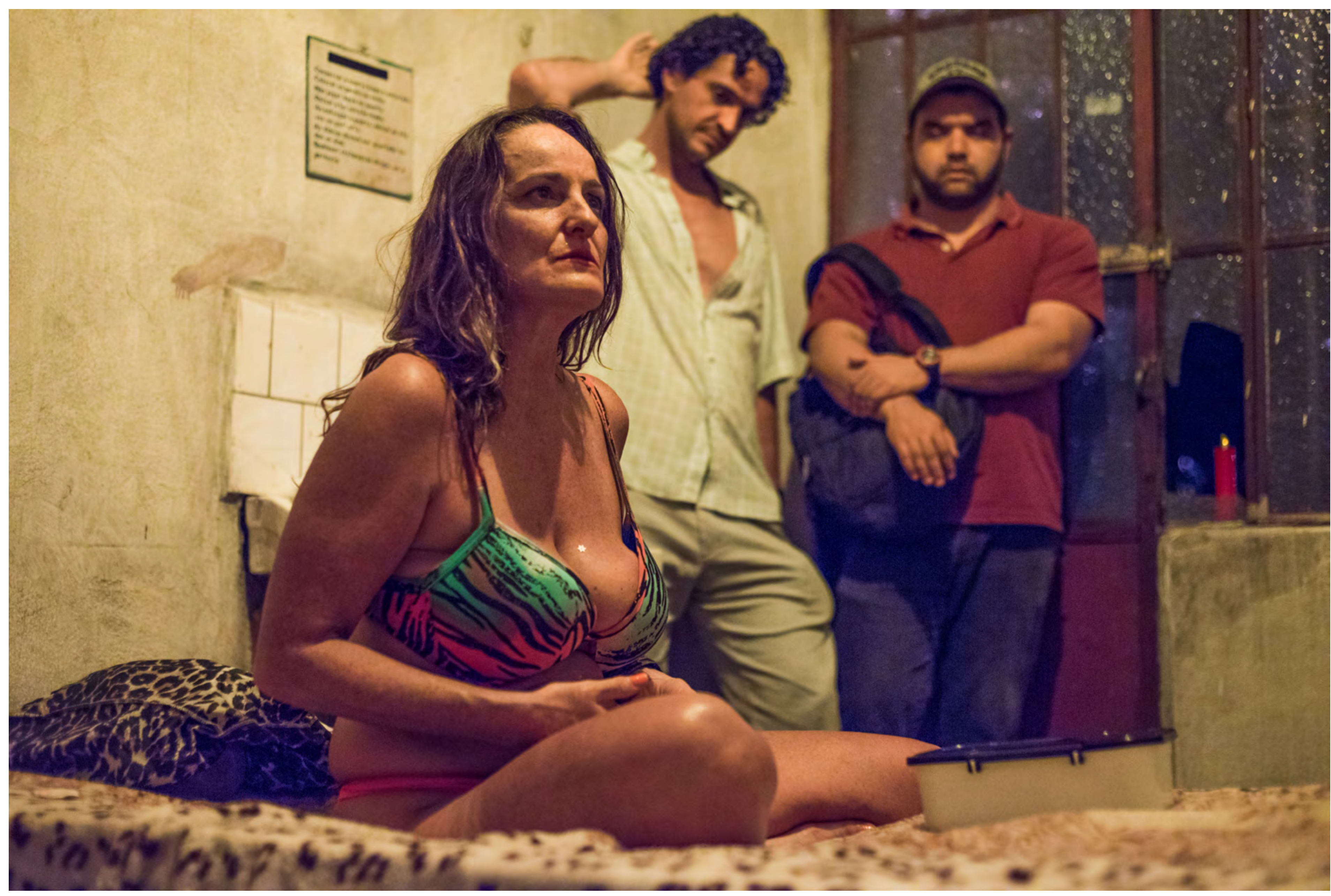




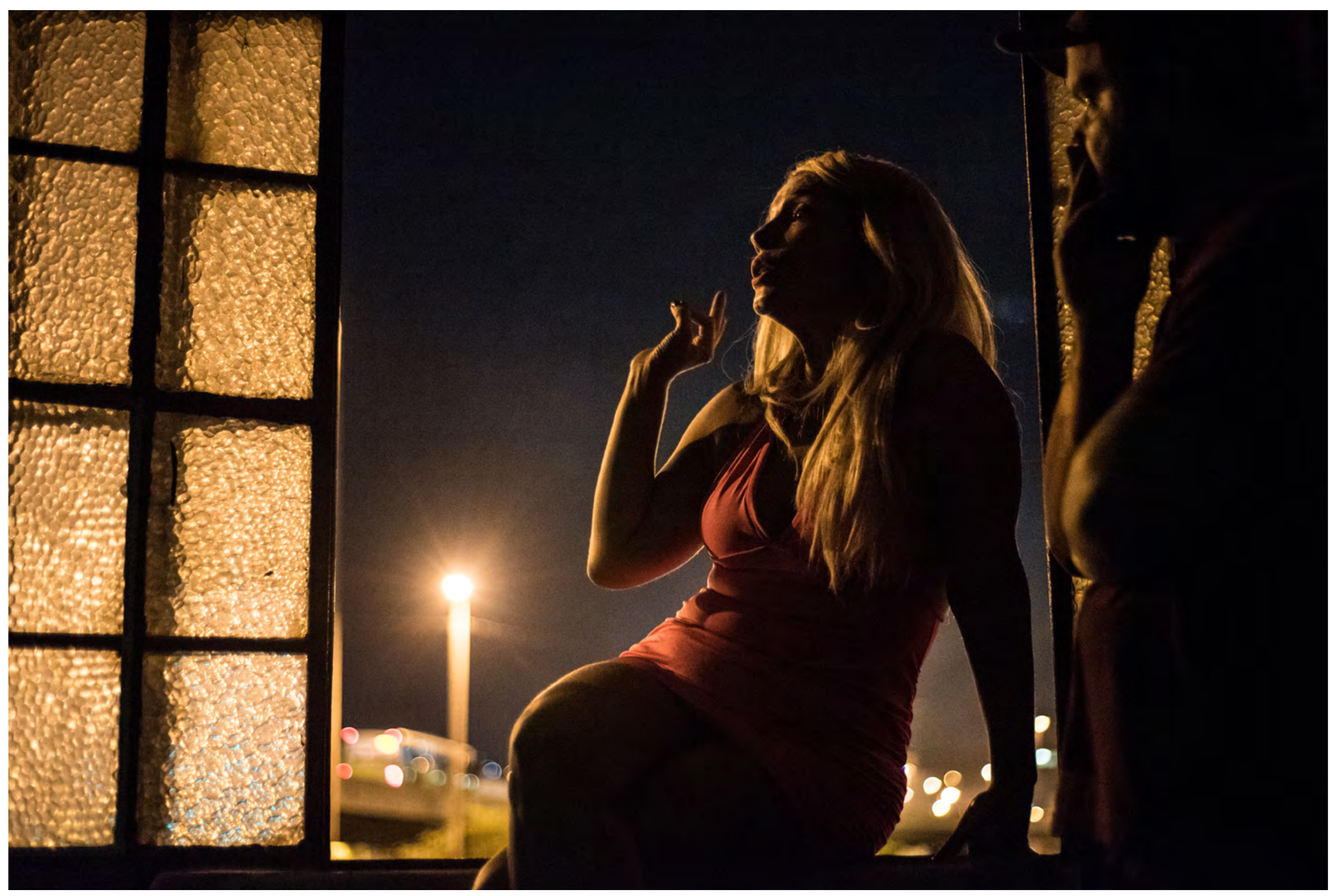




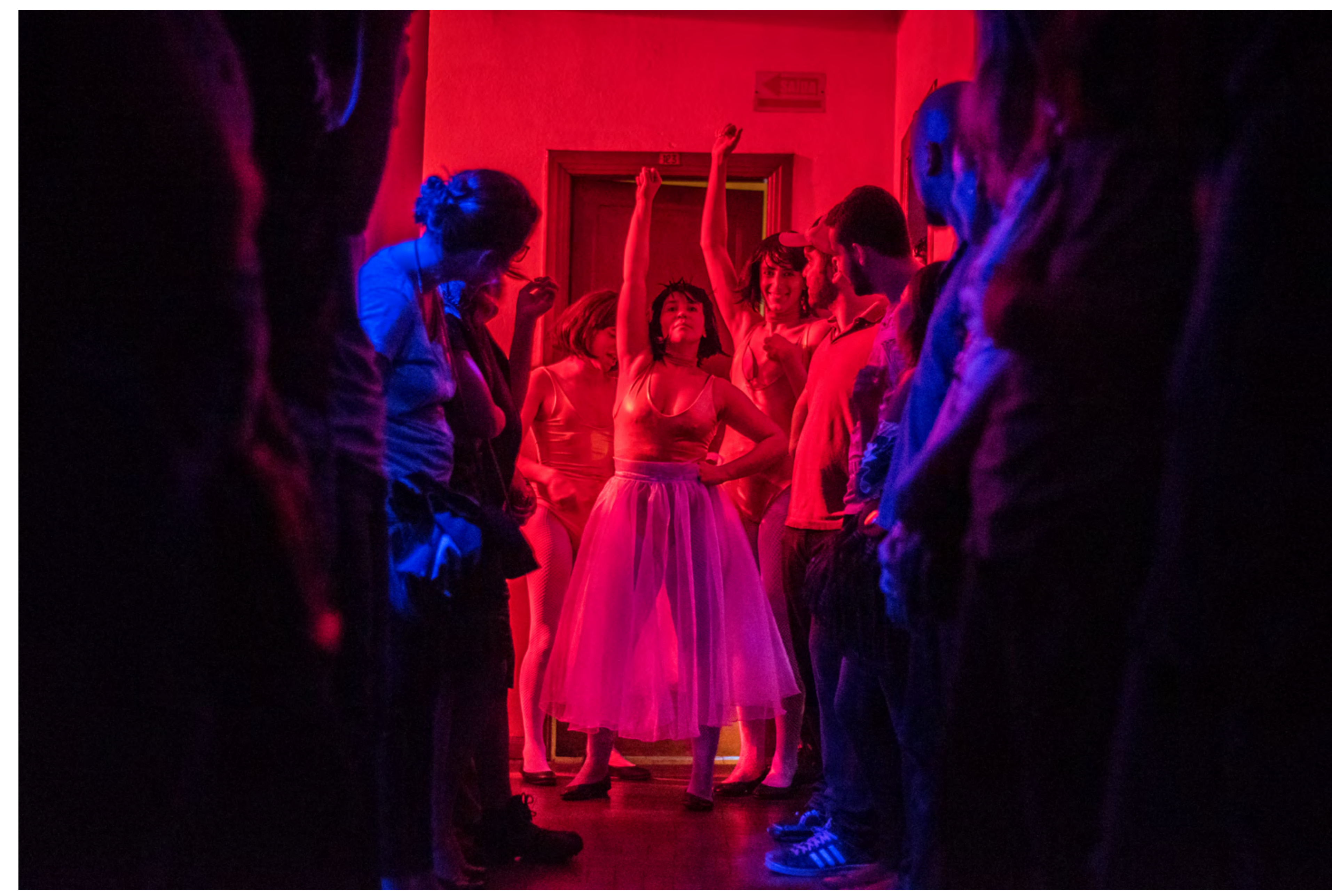




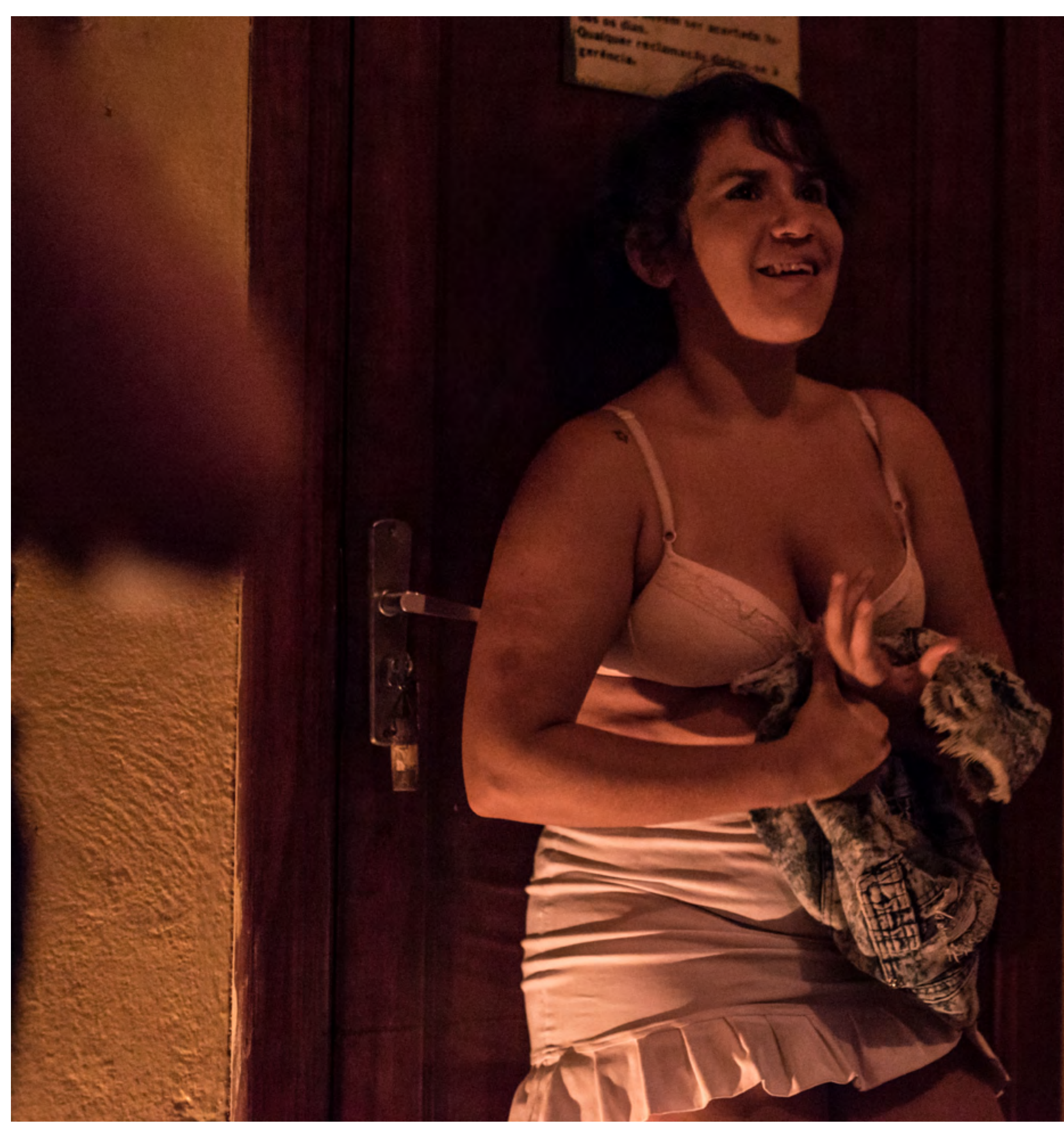




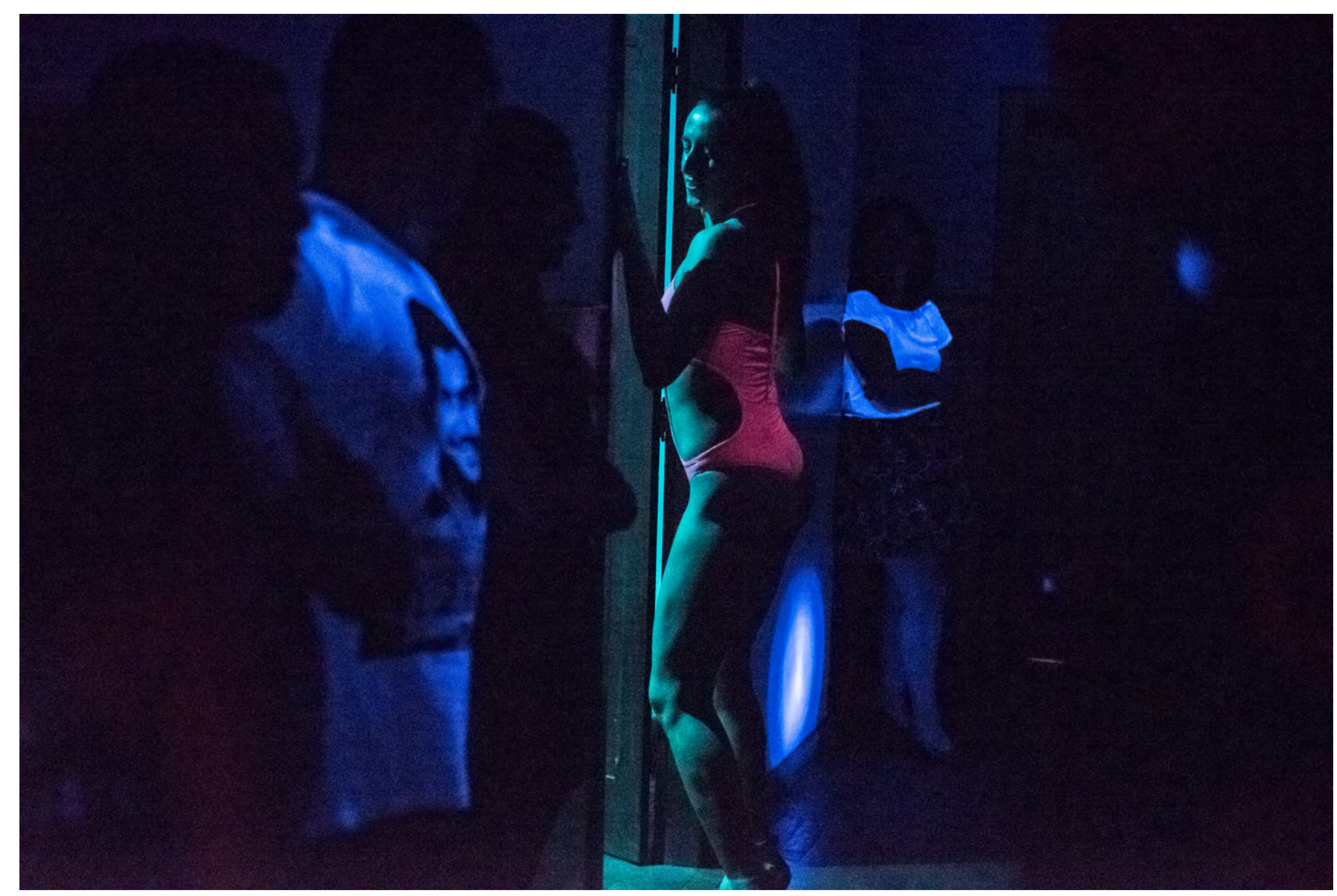




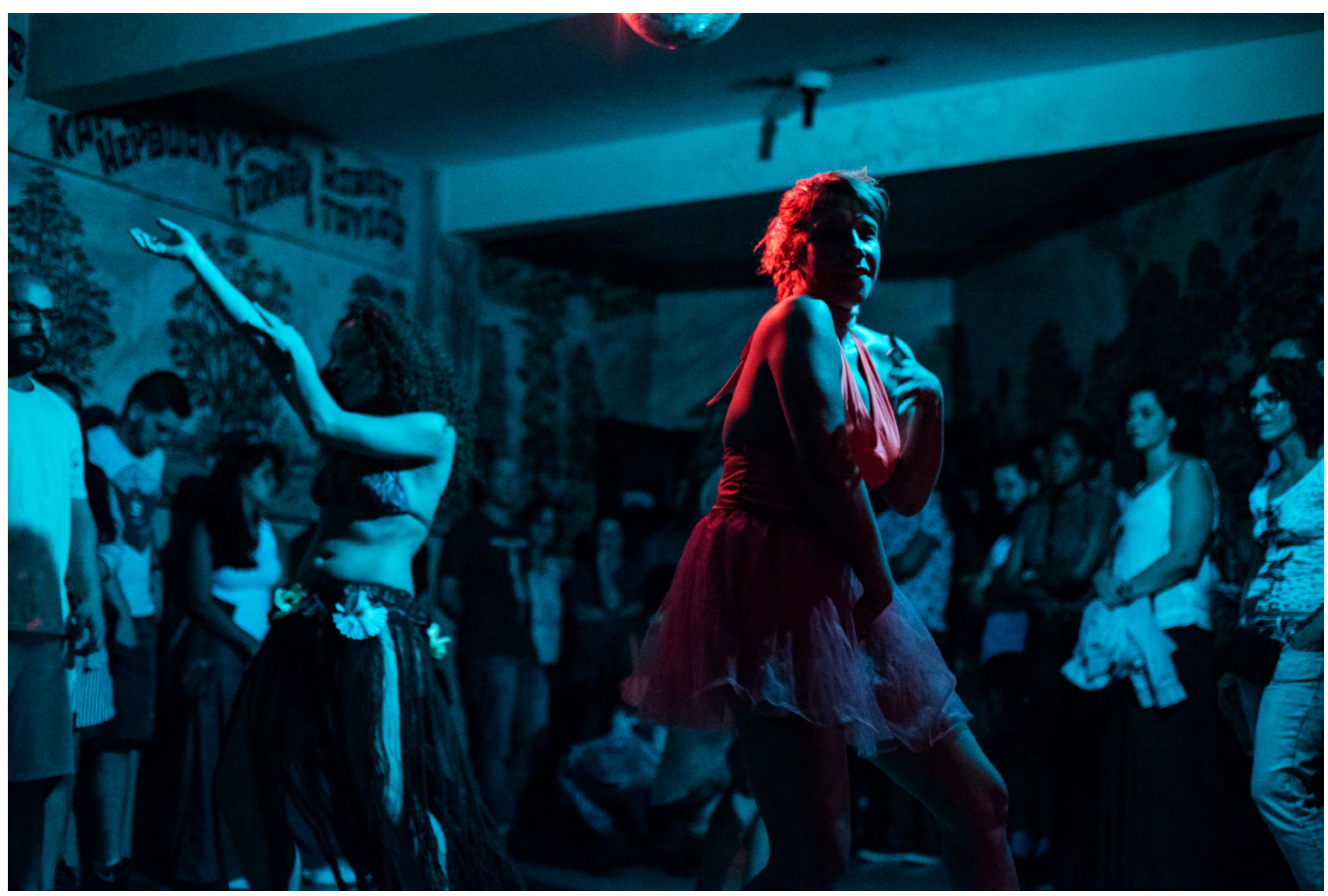

